\title{
FAKTOR-FAKTOR YANG MEMPENGARUHI PERILAKU KONSUMEN TERHADAP KEPUTUSAN PEMBELIAN HIJAB PADA SANTRIWATI DAYAH DARUL MUA'RIF AL-AZIZIYAH
}

Mukhlis Muhammad Nur ${ }^{1}$

Ichsan, LC., M.E.I ${ }^{2}$

Qudratul Munira $^{3}$

${ }^{1}$ Islamic Economics Department, Faculty of Economics and Business, University of Malikussaleh

${ }^{2}$ Islamic Economics Department, Faculty of Economics and Business, University of Malikussaleh

${ }^{3}$ Islamic Economics Department, Faculty of Economics and Business, University of Malikussaleh

1mukhlish.mnur@unimal.ac.id

2ichsan84@unimal.ac.id

39udratul.160440087@mhs.unimal.ac.id

\section{ARTICLE HISTORY}

Received:

11 April 2021

Revised

11 April 2021

Accepted:

20 May 2021

Online available:

19 June 2021

Keywords :

Culture, Social, Personal, Psychology, and Design,Purchase

Decisions.

*Correspondence:

Name:

Qudratul Munira

E-mail:

qudratul.160440087@mhs.unimal.ac.id

\section{ABSTRACT}

This study aims to determine the factors influencing consumer behavior towards the purchase decisions of Hijab among Dayah students of Darul Mua'rif Al-Aziziyah. This study uses primary data obtained by distributing questionnaires to 61 respondents selected using the Slovin formula. The data analysis method used is multiple linear regression with the help of SPSS. The results partially show that culture has a positive but insignificant effect on purchase decisions of Hijab at the Dayah students of Darul Mua'rif Al-Aziziyah, social has a positive and significant effect on purchase decisions of Hijab at the Dayah students of Darul Mua'rif Al-Aziziyah, person has a negative and insignificant effect on purchase decisions of Hijab at the Dayah students of Darul Mua'rif Al-Aziziyah, psychology has a positive and significant effect on purchase decisions of Hijab at the Dayah students of Darul Mua'rif AlAziziyah, and design has a negative and insignificant effect on purchase decisions of Hijab at the Dayah students of Darul Mua'rif Al-Aziziyah. Simultaneously, culture, social, person, psychological, and design have a significant effect on the purchase decisions of Hijab at Dayah of Darul Mua'rif AlAziziyah. 


\section{PENDAHULUAN}

Perkembangan kegiatan di dunia bisnis sekarang ini membuat perubahan di segala bidang, tidak ketinggalan dalam bidang pemasaran. Untuk dapat bersaing dalam dunia bisnis yang semakin maju ini. Pengaruh perilaku konsumen sangat penting dalam hal suatu usaha dalam memasarkan produknya. Perilaku konsumen sangat dinamis yaitu mudah berubah. Jadi hal ini dapat mempengaruhi kondisi dan situasi konsumen terhadap keputusan pembelian. Karena perilaku konsumen berhubungan dengan aktivitas seseorang dalam kegiatan pencarian, pemilihan, pembelian, serta penggunaan produk untuk memenuhi kebutuhan dan keiginan. Perilaku konsumen juga dapat menjadi hal yang sangat dipertimbangkan oleh para produsen dalam produksi dan pemasaran dari produk mereka.

Oleh karena itu, pemasar wajib mengetahui dan memahami keinginan daripada konsumen, baik itu selera, dan juga bagaimana konsumen mengambil keputusan dalam hal pembelian barang yang di inginkan. Adapun faktor- faktor perilaku konsumen yang memengaruhi keputusan pembelian itu terdiri dari faktor kebudayaan, faktor sosial, faktor pribadi, faktor psikologi dan faktor desain. Yang menjadi fenomena menarik dalam penelitian ini adalah apakah para santriwati dalam menggunakan hijab tersebut di pengaruhi oleh faktor tersebut atau dikarenakan tren fashion yang sedang marak sekarang ini.

\section{PENELITIAN TERDAHUU}

Aprilia (2017) “ Analisi Faktor-faktor Yang Mempengaruhi Perilaku Pembelian Online Pada Mahasiswa Yogyakarta" Penelitian ini merupakn penelitian menggunakan teknik purposive sampling. Data dalam penelitian ini dikumpulkan melalui teknik penelitian kuesioner dan penelitian lapangan (Field Research) dengan cara wawancara dan observasi. Dalam penelitian ini responden nya yaitu mahasiswa di 15 perguruan tinggi Yogyakarta yang terdiridari 5 subk elompok yakni universitas, sekolah tinggi, institusi, akademi dan politeknik.

\section{DESAIN PENELITIAN}

Penelitian ini menggunakan metode kuantitatif. Pendekatan kuantitatif bertujuan untuk menjelaskan fenomena atau gejala yang ada dengan menggunakan data-data numerik atau statistik sebagai bahan utama untuk melakukan analisisnya (Suharsaputra, 2014: 50). Metode pengambilan sampel yang digunakan dalam penelitian ini adalah nonprobability sampling, dimana elemen dari populasi tidak memiliki kesempatan yang sama untuk dipilih sebagai subjek penelitia, Kemudian teknik sampling yang digunakan adalah purposive sampling.

\section{HIPOTESIS PENELITIAN}

Persepsi manfaat berpengaruh positif terhadap perilaku pembelian online $\mathrm{H}$ 2: Persepsi risiko berpengaruh negatif terhadap perilaku pembelian online H3: Motivasi hedonik berpengaruh 
positif terhadap perilaku pembelian online H4: Faktor psikologis berpengaruh positif terhadap perilaku pembelian online H5: Desain website berpengaruh positif terhadap perilaku pembelian online H6: Persepsi manfaat, persepsi risiko, motivasi hedonik, faktor psikologis, dan desain website secara simultan berpengaruh terhadap perilaku pembelian online.

\section{METODELOGI PENELITIAN}

Metode analisis data merupakan kegiatan setelah data terkumpul (Sugiyono, 2015). Untuk memecahkan masalah pada penelitian ini maka penulis menggunakan metode analisis Linear Berganda, dengan memakai metode kuantitiatif yaitu suatu metode menganalisis data yang diperoleh dalam bentuk angka yang selanjutnya dibahas dan dianalisis menggunakan alat statistik yaitu program SPSS 22 yang berupa metode Regresi Linear Berganda (RLB) sebagai berikut:

$$
Y=\alpha+\beta_{1} X_{1}+\beta_{2} X_{2}+\beta_{3} X_{3}+\beta_{4} X_{4}+\beta_{5} X_{5}+e
$$

\section{HASIL DAN PEMBAHSAN}

Variabel Kebudayaan memiliki hubungan yang positif terhadap keputusan pembelian hijab, dengan nilai koefision sebesar 0.038 dengan tanda positif (+).Temuan ini menunjukkan bahwa apabila variabel Kebudayaan meningkat sebesar satu skala likert maka keputusan pembelian hijab akan meningkat sebesar 0,038 dan nilai signifikan sebesar $0.583>$ dari $\mathrm{p}$ value yaitu 0.05 , maka tidak terdapatpengaruh antara $x 1$ dengan $Y$. Sosial memiliki hubungan yang positiv terhadap keputusan pembelian hijab, dengan nilai koefision sebesar 0,193 dengan tanda positif (+).Temuan ini menunjukkan bahwa Sosial naik sebesar satu skala likert maka variabel keputusan pembelian hijab akan meningkat sebesar 0,193 dan nilai signifikan sebesar 0.015 < dari p-value yaitu 0.05, maka terdapat pengaruh antara x2 dengan Y. Pribadi memiliki hubungan yang positif terhadap keputusan pembelian hijab, dengan nilai koefisien sebesar 0,119 dengan tanda positif (+).Temuan ini menunjukkan bahwa apabila pribadi naik sebesar satu skala likert maka variabel keputusan pembelian hijab akan meningkat sebesar 0,119 dan nilai signifikan sebesar $0.065>$ dari $p$-value yaitu 0.05 , maka tidak terdapat pengaruh antara $x 3$ dengan Y. Psikologi memiliki hubungan yang positiv terhadap keputusan pembelian hijab, dengan nilai koefisien sebesar 0,244 dengan tanda positiv (+).Temuan ini menunjukkan bahwa apabila psikologi naik sebesar satu skala likert maka variabel keputusan pembelian hijab akan meningkat sebesar 0,244. nilai signifikan sebesar $0.010<$ dari $p$-value yaitu 0.05 , maka terdapat pengaruh antara $x 4$ dengan $Y$. Desain memiliki hubungan yang positif terhadap keputusan pembelian hijab, dengan nilai koefisien sebesar 0,070 dengan tanda positif (+).Temuan ini menunjukkan bahwa apabila desain naik sebesar satu skala likert maka variabel keputusan pembelian hijab akan meningkat sebesar 0,070 dan nilai signifikan sebesar $0.390>$ dari $p$-value yaitu 0.05 , maka tidak terdapat pengaruh antara x 5 dengan $\mathrm{Y}$ 
Berdasarkan hasil pada uji simultan diperoleh hasil bahwa nilai $F_{\text {hitung }}$ lebih besar dari Ftabel $(15,048>2.37)$ dan nilai signifikan $(\mathrm{sig})=0,000$ yang lebih kecil dari nilai $\alpha=0,05$. perhitungan regresi menunjukkan bahwa hipotesis alternative Ha diterima. Hal ini berarti variabel variabel kebudayaan $\left(X_{1}\right)$, sosial $\left(X_{2}\right)$, pribadi $\left(X_{3}\right)$, psikologi $\left(X_{4}\right)$, dan desain $\left(X_{5}\right)$ secara simultan atau bersama-sama berpengaruh signifikan terhadap keputusan pemeblian hijab.

Tabel Hasil Uji Parsial (Uji t)

\begin{tabular}{|c|c|c|c|c|c|c|}
\hline \multicolumn{7}{|c|}{ Coefficients $^{\mathrm{a}}$} \\
\hline \multirow{2}{*}{\multicolumn{2}{|c|}{ Model }} & \multicolumn{2}{|c|}{ Unstandardized Coefficients } & $\begin{array}{c}\text { Standardized } \\
\text { Coefficients }\end{array}$ & \multirow[b]{2}{*}{ T } & \multirow[b]{2}{*}{ Sig. } \\
\hline & & B & Std. Error & Beta & & \\
\hline 1 & (Constant) & 6.884 & 1.342 & & 5.129 & .000 \\
\hline & TOTAL_KEBUDAYAAN & .038 & .069 & .057 & .552 & .583 \\
\hline & TOTAL_SOSIAL & 193 & .077 & 298 & 2.500 & .015 \\
\hline & TOTAL_PRIBADI & 119 & .063 & 197 & 1.881 & .065 \\
\hline & TOTAL_PSIKOLOGI & 244 & .092 & .313 & 2.656 & .010 \\
\hline & TOTAL_DESAIN & .070 & .080 & 102 & .867 & .390 \\
\hline
\end{tabular}

Tabel Hasil Uji Simultan (F)

\begin{tabular}{|c|c|c|c|c|c|c|}
\hline \multicolumn{7}{|c|}{ ANOVA $^{a}$} \\
\hline & & Sum of Squares & $\mathrm{Df}$ & Mean Square & $\mathrm{F}$ & Sig. \\
\hline \multirow[t]{3}{*}{1} & Regression & 163.253 & 5 & 32.651 & 15.048 & $.000^{b}$ \\
\hline & Residual & 119.337 & 55 & 2.170 & & \\
\hline & Total & 282.590 & 60 & & & \\
\hline
\end{tabular}

\section{KESIMPULAN}

Berdasarkan hasil penelitian diatas dapat disimpulkan bahwa semua variabel yaitu X1 (kebudayaan), X2 (sosial), X3 (pribadi), X4 (psikologi), X5 (desain) memiliki nilaip-value lebih besar dari 0,05 yang berarti semua variabel positif dan hanya dua variabel yaitu X2 (sosial) dan X4 (psikologi) yang memiliki nilai signifikan lebih besar dari 0,05 sedangkan tiga variabel lagi yaitu X1 (kebudayaan), X3 (pribadi), dan X5 (desain) memiliki nilai signifikan lebih kecil dari 0,05 . Nilai adjusted $R$ square menunjukkan besarnya konstribusi pengaruh variabel bebas terhadap variabel terikat dalam sebuah model. Hasil perhitungan yang disajikan pada tabel diatas menunjukkan nilai adjusted $R$ square $=0,539$ atau 53,9\%. Hal ini berarti bahwa sebesar 53,9\% keputusan pembelian hijab dapat dijelaskan dan dipengaruhi oleh variabel kebudayaan $\left(X_{1}\right)$, sosial $\left(X_{2}\right)$, pribadi $\left(X_{3}\right)$, psikologi $\left(X_{4}\right)$, dan desain $\left(X_{5}\right)$ sedangkan sisanya $46,1 \%$ dipengaruhi oleh variabel lain yang tidak termasuk dalam penelitian. 


\section{REFERENSI}

Anwar, S. (2000) Realibilitas dan Validitas. yogyakarta: pustaka belajar.

Asis, P. H. (2017) 'Makna Berhijab Bagi Muslimah: Sebuah Persepsi Mahasiswi

Aprillia, (2017). Analisis Faktor-faktor yang Mempengaruhi Perilaku Pembelian Online pada Mahasiswa Yogyakarta. Skripsi S1 (Dipublikasi). Fakultas Ekonomi Universitas Negeri Yogyakarta

Arifuddin, Azwita. (2012). Faktor-faktor yang Mempengaruhi Perilaku Konsumen dalam Keputusan Membeli Komputer di Lingkungan Mahasiswa di Fakultas Ekonomi dan Bisnis Universitas Hasanuddin. Skripsi S1 (Dipublikasi).Fakultas Ekonomi dan Bisnis Universitas Hasanuddin Makassar.

Fisip Universitas Muhammadiyah Kendari', Jurnal Dakwah Tabligh, 18(2), pp 237-251. doi: $10.24252 / j d t . v 18 i 2.4703$.

Aswadi Lubis, Rodame Monitorir Napitupulu, Rosnita Fitri, (2018) 'Faktor- faktor Yang Memengaruhi Keputusan Pembelian Hijab Merak Rabbani, I, 6, pp. $\quad 38-57$ Cv, P., Asysa. Padangsidimpuan

Etta mamang, S. (2013) Perilaku Konsumen, Pendekatan Praktis Disertai Himpunan Jurnal Penelitian. Yogyakarta: cv. Andi Offest.

Ghozali, I. (2006) Aplikasi Analisis Multivariate Dengan Program SPSS. Semarang: Badan Penerbit Universitas Diponegoro. 